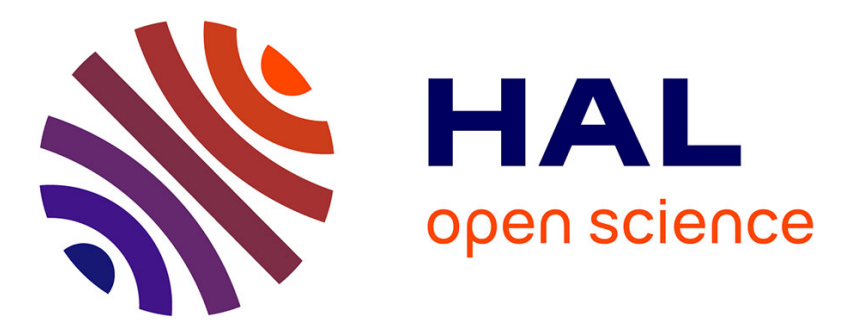

\title{
Partial-profilogram reconstruction method to measure the geometric parameters of wheels in dynamic condition
}

E. J Bernal, Ronald Martinod, G. R Betancur, L.F Castañeda

\section{To cite this version:}

E. J Bernal, Ronald Martinod, G. R Betancur, L.F Castañeda. Partial-profilogram reconstruction method to measure the geometric parameters of wheels in dynamic condition. Vehicle System Dynamics, 2016, 54 (5), pp.606-616. 10.1080/00423114.2016.1147588 . hal-02160027

\section{HAL Id: hal-02160027 \\ https://hal.science/hal-02160027}

Submitted on 19 Jun 2019

HAL is a multi-disciplinary open access archive for the deposit and dissemination of scientific research documents, whether they are published or not. The documents may come from teaching and research institutions in France or abroad, or from public or private research centers.
L'archive ouverte pluridisciplinaire HAL, est destinée au dépôt et à la diffusion de documents scientifiques de niveau recherche, publiés ou non, émanant des établissements d'enseignement et de recherche français ou étrangers, des laboratoires publics ou privés. 


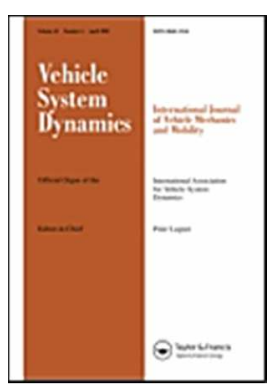

\section{Partial-profilogram reconstruction method to measure the geometric parameters of wheels in dynamic condition}

\begin{tabular}{|r|l|}
\hline Journal: & Vehicle System Dynamics \\
\hline Manuscript ID & Draft \\
\hline Manuscript Type: & Original Paper \\
\hline Date Submitted by the Author: & n/a \\
\hline Complete List of Authors: & $\begin{array}{l}\text { Bernal, Esteban; EAFIT University, Mechanical Engineering } \\
\text { Martinod, Ronald; EAFIT University, Mechanical Engineering } \\
\text { Betancur, German; EAFIT University, Mechanical Engineering } \\
\text { Castañeda, Leonel; EAFIT University, Mechanical Engineering }\end{array}$ \\
\hline Keywords: & $\begin{array}{l}\text { dynamic measuring, geometric parameters, profilogram, railway testing, } \\
\text { wheel profile }\end{array}$ \\
\hline
\end{tabular}

\section{SCHOLARONE ${ }^{m}$}

Manuscripts 


\title{
Partial-profilogram reconstruction method to measure the geometric parameters of wheels in dynamic condition
}

\author{
E.J. Bernal, R.M. Martinod, G.R. Betancur, and L.F. Castañeda* \\ Mechanical Engineering Department, Universidad EAFIT, Medellin, Colombia
}

Ronald Mauricio Martinod

E-mail: rmartino@eafit.edu.co

Address: Carrera 49 N $^{\circ} 7$ Sur 50 of. 14-203,

Medellin (Colombia - South America)

Phone number: (57) (4) - 2619500 ext. 9368

Gerrmán René Betancur

E-mail: gbetanc4@eafit.edu.co

Address: Carrera $49 \mathrm{~N}^{\circ} 7$ Sur 50 of. 14-203,

Medellin (Colombia - South America)

Phone number: (57) (4) - 2619500 ext. 9896

Esteban de Jesús Bernal

E-mail: ebernala@eafit.edu.co

Address: Carrera 49 N $^{\circ} 7$ Sur 50 of. 14-203,

Medellin (Colombia - South America)

Phone number: (57) (4) - 2619500 ext. 9896

Leonel Francisco Castañeda

E-mail: 1casta@eafit.edu.co

Address: Carrera $49 \mathrm{~N}^{\circ} 7$ Sur 50 of. 14-203,

Medellin (Colombia - South America)

Phone number: (57) (4) - 2619500 ext. 9145

*Corresponding author 


\section{Partial-profilogram Reconstruction Method for Measuring the}

\section{Geometric Parameters of rail wheels in a dynamic condition}

The present work poses a method for the measurement of geometric parameters of rail wheels in a dynamic condition, by reconstructing the profilogram from a portion of the wheel surface wear with artificial vision. The suggested procedure can work with a two-dimensional laser displacement transducer or by processing a sole image from a single camera with a structured light source. These two procedures require fewer devices and simpler implementation processes and allow the use of mathematical algorithms that demand less information processing, thus generating more accurate results. Railway operators may implement this method to perform predictive maintenance to their rolling stock at a fraction of the regular cost; thus achieving better precision, availability, maintenance performance and improving safety. Results were compared to those given by commercial equipment, showing similar precision but a better cost-benefit relation.

Keywords: dynamic measuring, geometric parameters, profilogram, railway testing, wheel profile.

\section{Introduction}

The tread surface wear of the rail wheels is a well-known phenomenon.[1-3] It increases operation costs and reduces safety during motion.[4] According to the UIC 510-2 code,[5] railroad operators must conduct inspections intended for the preservation of the wheel profile geometric parameters: (i) the wheel radius $-R-$; (ii) the radius difference $-\Delta R-$; (iii) the flange height and thickness $-s_{h}$ and $s_{d^{-}}$; and (iv) the flange slope $-q_{R^{-}}$. Large railway operators spend considerable amounts of time and money inspecting, repairing and replacing wheels. The inability to identify wheel damages in an easy, accurate, rapid and correct manner is quite dangerous — since worn wheels are a major cause of derailments — but it certainly forces an interruption of the regular railroad operation throughout the processes of inspection and replacement of condemnable wheels, i.e., wheels with profiles beyond the tolerance 
range.[6] Consequently, wayside measuring of wheel profile geometry becomes imperative.

The state of art includes the developments WO2001007308A1, WO2004058554A1 and EP1614602A1,[7-9] among others, that have exposed devices capable of measuring roundness of wheels through mechanical systems and recording the radius of the flange tip according to the fact that the perimeter of the wheel flange is precisely round and the shape of the flange tip is neither affected nor worn.

Therefore, the flange tip can be used as a reference for measuring the wheel diameter. In practice, inspections performed by mechanical contact systems show many limitations due to the device complexity, e.g., the profile measurements must be conducted in the repair shop; and since the access to the mounted wheels is complicated, dissembling of the bandage is preferable. Although the measurement of all the profile geometric parameters is impossible, using the flange tip to determine them was a reliable reference for the method introduced in this work.

Artificial vision systems are the appropriate solution to the problem because they enable automatic wayside profile measurements in dynamic condition without disturbing the normal exploitation of the railroad. [6] Previous studies have addressed their inspections by calculating the geometric parameters, via artificial vision systems, with special installations arranged along the rail. [10-12] The linear light sensor device is the most commonly used instrument to assess the geometric parameters of train wheels. [12-14] The US5808906 [15] invention, by using two devices, sets out a two-stage procedure: (i) the estimation of the wheel profile which requires for a modified rail for the wheel so that it rests on the exterior carriageway; and (ii) the actual measuring of the diameter, which requires a staged modified rail such as the wheel resting on the flange. Under these circumstances, the train guidance is 
canceled, thus transgressing standards and regulations regarding the driving safety of railway vehicles.

The development US6003232 [16] proposes a method for online assessing of the train wheel geometric parameters which requires an installation of a linear light vision sensor on a specially modified rail, resulting problematic for the railway operation. Ciobata et al. [17] developed a system installing two line structured light vision sensors and several laser displacement transducers for dynamically measuring of geometric parameters of train wheels. Another development, the WO2004046644A2,[6] presents a method using a synchronized set of laser light sources and cameras in which the profile measurement depends on the record of all the images to obtain the wheel profile parameters. Simultaneous processing of all images generates a sampling frequency decrease in the measurement and reduces its accuracy.

The US2003160193A1 [18] invention raises two linear laser light sources creating a single line over the wheel's surface, these lasers must satisfy two conditions: (i) they must be arranged collinearly, and (ii) they must overlap. It also entails processing of a wheel profile image — directly acquired by the camera - and a second image taken with a set of mirrors; so that each view shows a different portion of the profile. Lastly, the development WO9012720 [19] presents an installation of a light source that projects a transverse line to the wheel, which is then captured by a camera, this installation requires several additional devices: (i) elements attached to a lighting unit for measuring the wheel diameter, and both (ii) light sources and cameras to capture the lighted up section close to the side edge of the wheel.

These revised methods are limited to the use of cameras for capturing images that completely register the wheel profile or diameter; thus representing a considerable 
load generated by each device in terms of image-set data processing, as well as implementation and maintenance of the devices that turned complex and expensive.[9]

This paper proposes a method for measuring geometric parameters of the train wheel profile $\left(s_{h}, s_{d}, q R\right)$ in dynamic condition. The work focuses on the measurement of a tread surface fraction of the wheel cross-section using artificial vision, to obtain a partial-profilogram, and hence a methodology was developed in order to reconstruct a complete profilogram for the consequent quantification of each geometric parameter.

\section{Measurement Method}

The setting up for dynamical measuring of the wheel diameter is shown in Fig. 1. Only one laser transducer was used; a laser transducer is a structured light source that projects a light beam which then gets reflected as a light line on the wheel $(y$ direction) while matching the rail transversal axis. Experimental evidence, as obtained from on running tests, showed that railway vehicles experience a hunting motion in dynamic condition when: (i) running on tangent tracks; and (ii) negotiating curves.[20] Then, during calculations, the wheelset has an attack angle, $\psi$, formed by the angular deviation between the wheel symmetry axis $y^{\prime}$ and the rail transversal axis. It is possible to find the $\psi$ value by using the geometric relation between two distance sensors, placed transversally on the track, to register the distances amid $y_{t r}$ and $y_{t c}$ on the wheel inner face; all by using the expression

$$
\psi=\arctan \left(a b s\left(y_{t r}-y_{t c}\right) x_{t}^{-1}\right)
$$

\subsection{Polynomial fitting of the measured wheel profile}


Every time wheel profiles get measured while in dynamic condition a noisy point cloud with locally non-uniform distributions is obtained; in particular with data processing techniques based on with artificial vision systems. Given a finite set of points sampled from a curve, representing a fraction of the wheel profile, $S$ (see Fig. 2). The stochastic points $S=\left\{p_{1}, \ldots, p_{k}, \ldots, p_{n}\right\}$, with a sequence of $n$ points, are sampled by following systematically ordered patterns, i.e. the data $P_{i}$ has connectivity with $P_{i+1}$. In this case, the order of the sampled points must be respected, and parametric methods can be applied to find the mathematical expression, $g$, of such a set $S$.[21] The mathematical expression $g=C_{i}(u)$ is a piecewise-defined parametric curve with $C_{i}(u)=\left(x_{k}(u), z_{k}(u)\right)$ and the parameter $u$ is one of the many possible ways to parameterize the $i$-th curve $C_{i}$. The parametric curve $C_{i}$ proposed by Bézier, De Casterljeau, and others, is expressed as[22]

$$
C_{i}(u)=\sum_{k=l}^{m} B_{k}(u) p_{k}
$$

with $0 \leq u \leq 1$ and $\sum_{k=l}^{m} B_{k}=1 . B_{k}(u)$ is known as Bernstein polynomial, in which the $k$-th represents the weight coefficient for the $k$-th point belonging to the subset $p_{c t l}$ of each stage partition of $S$; the subset referred as Control point is defined as $p_{c t l}=\left\{p_{l}, \ldots p_{k}, \ldots, p_{m}\right\}$ where $l \geq 1$ and $m \leq n$. The spline curve is a numeric function piecewise-defined by polynomial functions $C_{i}(u)$, to which the piecewise spline interpolation is appropriate because it yields similar results while interpolating higher degree polynomials and avoids instability caused by the Runge's phenomenon.[23]

The properties of parametric curves are concentrated in their coefficient set $B_{k}(u)$, then, to obtain the polynomial fitting of the wheel profile, the used piecewise-defined parametric curves are cubic-splines (specifically, uniform B-spline), which in the overlapping control points, in consecutive stages, allows fulfilling of the wheel profile 
continuity requirements: $C^{1}$ (tangent-continuous) and $C^{2}$ (curvature-continuous).[22, 24]

\subsection{Partial-profilogram via geometric transformation}

In the case of rail wheels (i.e. solid bodies with basic cylindrical or annular shapes), the fitted parametric curves $g$ describe the revolution surface (fraction of the tread surface) on the direction of coordinate frame $\mathrm{E}=[y, z, o]$, and can be geometrically transformed on the direction of coordinate frame $E^{\prime}=\left[y^{\prime}, z^{\prime}, o^{\prime}\right]$, which corresponds to the wheel cross section (see Fig. 3). Therefore, the coordinate frame E suffers changes that are caused by non-rigid geometric transformations $f(E(\psi))$ because of the attack angle $\psi$. Moreover, defining the effects of the geometric transformation on the coordinate frame $E^{\prime}$ guarantees that the parametric curve $g$ suffers such effects as a whole.[22]

The geometric transformation $f(E(\psi))=E^{\prime}$ implies that $f$ transforms $E$ to yield $E^{\prime}$. As it turns out $f$ is a linear function and its application can be expressed as $E^{\prime}=f \cdot E$, and $f$ is expressed in the following matrix expression $f=\left[(\cos \psi)^{-1},-1\right.$, $1]^{T}$. Numerically, this equation effectively transforms the parametric curve $g$ into the partial-profilogram $G$, then

$$
\mathrm{G}=\mathrm{f}(\mathrm{E}(\psi)) \cdot \mathrm{g}
$$

Take note of the $l_{m}(y$ direction) length measured and transformed into the real length of the wheel cross section; $l_{r}$ ( $y^{\prime}$ direction), as a function of the coordinated vector projection $y^{\prime}$ over the coordinated vector $y$, i.e. $l_{r} \cos \psi=\operatorname{Proy}\left(y^{\prime}{ }_{y}\right)$; hence the likelihood to find a direct expression to obtain the true length of the partialprofilogram, $l_{r}=l_{m}(\cos \psi)^{-1}$. 


\subsection{Partial-profilogram reconstruction}

The wheel wear is more noticeable towards the centre of the tread, this intense wear effect is caused even with the use of stable running bogies, significant wear in the centre of the tread develops a so-called false flange on the side of the wheel; [25] in contrast with the tread wear, the flange wear may lead to an increase of the flange angle and a reduction of the flange thickness;[26] furthermore, the wheel climb is limited by the high value of conicity in the flange face, and the Nadal formula which depends on the wheel flange maximum contact angle.[27] As a result, the train wheels are not designed for the wheel climb effect, and the wearing occurs on the following profile sections: (i) the tread surface wear, (ii) the flange root, and (iii) the flange face. Flange tip rollover is only an issue affecting trams and light-rail vehicles exposed to flange tip running on grooved rails or on negotiating tramway switches and crossings.[25]

The partial-profilogram reconstruction $G$ is based on the well-known fact that flange tips $F_{t}$ of railway vehicle wheels are not affected by the normal wear of operating trains.[7-9] Therefore, the unregistered profile fractions of the partialprofilogram $G$ can be reconstructed using a profilogram $H$ as a standard reference measure of wheel profiles (see Fig. 4).

The profilogram $G=\left\{p_{1}, \ldots, p_{n}\right\}$ enables the flange tip $F_{t}$ identification equivalent point among these profilograms_-, according to the expression

$$
\mathrm{F}_{\mathrm{t}}=\min (\mathrm{G}) \equiv \min (\mathrm{H}) \text {. }
$$

The dimensions $l_{m}$ and $l_{n}$ define the true length of the partial-profilogram $G$, $l_{r}=l_{m}+l_{n}$; then, the splitting of $H$ into three sections is possible: $H_{F}=$ $\left\{h_{1}, \ldots, h_{f-1}\right\}, H_{T}=\left\{h_{f}, \ldots, h_{k}\right\}$ and $H_{E}=\left\{h_{k+1}, \ldots, h_{m}\right\} ;$ where 
$\left\{h \in H \quad \mid h(i, j)\right.$ with $\left.\left(i \in y^{\prime}\right) \wedge\left(j \in z^{\prime}\right)\right\}$ and $H_{T}$ holds the length $l_{r}$, i.e. $H \subset$ $\left\{H_{F}, H_{T}, H_{E}\right\}$.

The reconstructed-profilogram $G_{H}$ is formed by three sections, $G_{H} \subset\left\{H_{F}, G, H_{E}\right\}$, and $G_{H}$ has the $l_{t}$ length. Note that $l_{t}$ (the wheel width) has a fixed value, nonaffected by the wheel rolling wear (see Fig. 5).

\subsection{Reconstructed-profilogram processing}

According to the international railway standards,[5] the $q_{0}=70 \mathrm{~mm}$, the $q_{1}=$ $10 \mathrm{~mm}$, and the $q_{2}=2 \mathrm{~mm}$ are the reference quotas (see Fig. 6). Locating the reference points $\left(p_{a}, p_{b}, p_{c}\right)$ on the reconstructed-profilogram $G_{H}: p_{a}\left(y_{a}, z_{a}\right)$, with $y_{a}=y_{0}+q_{0} ; p_{b}\left(y_{b}, z_{b}\right)$, with $z_{b}=z_{0}+q_{1}$; and $p_{c}\left(y_{c}, z_{c}\right)$, with $z_{c}=z_{0}+q_{2}$; it is possible by using a first-order - or superior - interpolation method.

The parametric approach for the wheel surface wear geometric characterization is based on the measurement of the profile parameters $\left(s_{h}, s_{d}, q_{R}\right)$ and expressed as $s_{h}=z_{a}-z_{0}, s_{d}=y_{b}-y_{0}$, and $q_{R}=y_{b}-y_{c}$.

The flange tip circumference radius $R_{t}$ is defined by the distance between the wheel symmetric axis and the flange tip $F_{t}$, thus according to the standard wheel reference value; because the wheel flanges are not subject to wear, is possible to find the nominal diameter $R$ by the difference between the lengths of the circumference radius of the flange tip $R_{t}$ and the flange height $s_{h}$, i.e., $R=R_{t}-s_{h}$.

\section{Test development}

From a variety of wheel profiles, the main common features among vehicles typically include a profile width of $125-135 \mathrm{~mm}$ and a flange height of $28-30 \mathrm{~mm}$; normally, the flange inclination angle is between $65 \mathrm{deg}$ and $70 \mathrm{deg}$. The common rolling stock conicity near the tape circle is either $1: 10$ or $1: 20 .[25]$ 
The current study is applied to passenger vehicles from the urban railway system of Medellin (Colombia) that are similar in geometry and design to the ET420 train sets formerly operated by Deutsche Bahn (e.g. the Munich S-Bahn), [28] the wheels have an S1002 profile.[29] These P-III category vehicles (EN 12663) are formed by two units, each one with two engine coaches (A and B) and one trailer coach. Each coach has two bogies with four wheels in two axles at a distance of $2300 \mathrm{~mm}$ (and a total weight of 113.3 ton). Vehicles transit at $2 \mathrm{~km} / \mathrm{h}$ through the equipment, where they are identified using RFID; then each wheel is measured and the data processed in less than 2 minutes. The equipment was installed in an auxiliary track of the urban railway system of Medellin located in the railroad repair shop. The equipment is contained in a pit under this auxiliary track, allowing housing for and protecting of all its components (Figure 7a). It is formed by two cameras, two linear laser projectors, eight distance transducers, two photoelectric barriers and the acquisition equipment. The cameras have a 2/3 CCD progressive type sensor, capable of generating images up to $1600 \times 1200$ pixels at $66 \mathrm{fps}$. The lenses are $51 \mathrm{~mm}$ diameter with a focal distance of $35 \mathrm{~mm}$ and an iris range from F1.4 to F22. The laser line projectors produce a $635 \mathrm{~nm}$ red light and have a power of $30 \mathrm{~mW}$. All these elements cost USD $\$ 90.000$ and are distributed as shown in the Figure $7 \mathrm{~b}$.

By using the measurement equipment, the tread surface wear and the XY coordinates are obtained. Additional data for the reconstruction are collected from the theoretical profile. The reconstructed profilogram is shown in Figure 8.

All datasets recorded are available from the authors of this paper. As an example of results, Figure 8 shows the data obtained after experimental field tests results imaging processing. 


\section{Validation}

In order to acknowledge the quality of the results obtained employing the proposed method, a validation through direct comparison of measurements between two commercial devices and the reconstructed-profilogram is conducted.

An equipment widely used is the MiniProf; in this case, the measuring head consists of two rotatory arms with optical encoders that are used to determine the position of a magnetic measuring wheel. As the operator moves the measuring wheel around the profile, the signals from the encoders are logged. The wheel profile is calculated from the position of the two arms recorded by the encoders applying suitable corrections to the varying contact positions in the measuring wheel itself.[1, 30]. Other commonly used equipment is the LazerView, it is a non-contact measuring device that uses magnets to approximate itself to the wheel, the head rotates a onedimensional laser transducer to obtain the coordinates of the points forming the wheel profile.

Is evident that the previously described equipments require static conditions during measuring. The train must be taken to a special track and some components must be unmounted, allowing access to the wheels. Also, qualified staff must perform the measurement one wheel at the time.

A series of measurements were conducted using three different methods, $M_{i}$ with $i=1,2,3$, which represent measurements using MiniProf, LazerView and proposed method; correspondingly. It is assumed that the measurements performed with MiniProf and LazerView are reference values, thus it is possible to find the existent measurement error in the values obtained through the proposed method. $\varepsilon_{i}=$ $\frac{M_{i}-M_{3}}{M_{i}} 100$. The Table 1 shows the comparison of the results obtained in the validation. 
The minimum error occurs in the parameter $S_{h}$, while measuring and comparing it with the value obtained using the static instruments. The maximum error occurs in the $q_{R}$ parameter, comparing it with the one measured with the MiniProf.

\section{Conclusions}

Monitoring of rail wheel wear is a requirement from the international standards for the safety operation. The local cost of performing this control, using the standard static equipment, on a train set of 24 wheels, which implies removing the train from commercial service and conduct it to a special track, is more than USD \$20 and takes about 4 hours to complete. On the contrary, by using the proposed method, the uniquely required operation is running the unit through the automated measuring equipment installed in the auxiliary track, which costs about USD $\varnothing 68$ for each train unit and takes less than 2 minutes.

The previously used development suggested the use of digitalized images from a set of cameras and laser light sources, or mirror arrangements and other components, so that each element captures a part of the profile, that represented a considerable load in the processing of all images generated by each device, as well as the implementation and maintenance of the devices becoming complex and expensive. The proposed method for measuring focusses on measuring only a fraction of the tread surface wear cross-section of a railway wheel, obtaining a partial-profilogram by image processing. Then, a methodology is developed to reconstruct the complete profilogram to measure each geometric parameter. At that point, the proposed method obtains a numerical description of the train wheels transverse profile -profilogrambased on a method with the single data system.

The proposed method may be implemented using a two-dimensional laser displacement transducer or a single image from a single camera with a structured light 
source, generating: (i) lower number of devices for the measurement; (ii) lower implementation complexity; and (iii) mathematical algorithms that require less information processing, generating more accurate results in the measurement.

The tests based on the proposed method were executed on the basis of UIC standards and regulations. The wheel profile parameters give technical information about the wear assessment; is the basis to configure a diagnosis monitoring system in which condition-based maintenance decisions should be taken (re-profiling, invalidation or parts replacement, etc.).

\section{References}

[1] Esveld C. Modern railway track. Delft: Delft University of Technology; 2001.

[2] Olofsson U, Lewis R. Tribology of the wheel-rail contact. In: Iwnicki S, editor. Handbook of Railway Vehicle Dynamics. Boca Ratón (FL): Taylor \& Francis; 2006. p. 121-142.

[3] Asadi A, Brown M. Rail vehicle wheel wear prediction: a comparison between analytical and experimental approaches. Veh Syst Dyn: Int J Veh Mech Mob. 2008; 46(6):541-549.

[4] Rezvani MA, OwhadiA, Niksai F. The effect of worn profile on wear progress of rail vehicle steel wheels over curved tracks, Veh Syst Dyn: Int J Veh Mech Mob. 2009; 47(3): 325-342.

[5] the International Union of Railways. UIC 510-2 Code. Trailing Stock: Wheels and Wheelsets. Conditions Concerning the Use of Wheels of Various Diameters. Paris; 2004.

[6] Kambiz N, inventor; Beena Vision Systems, Inc., assignee. Wheel profile inspection apparatus and method. International patent WO2004046644-A3. 2003 July 8.

[7] James KC, Gehan RW, Villanueva A, inventors; AEA Technology, Plc., assignee. Railway wheel monitoring. International patent WO2001007308-A1. 2001 Feb 1.

[8] Heimann A., inventor; Hegenscheidt Mfd, Gmbh \& Co., assignee. Device for measuring the roundness of a railroad wheel. International patent WO2004058554-A1. 2004 July 15 .

[9] Ehmke F, Groll P, Müller R, inventors; Schenck Process Gmbh, assignee. Device for measuring of condition data of a rolling wheelset of a rail-bound vehicle. European Patent EP1614602-A1. 2011 May 4.

[10] Medianu SO, Rimbu GA, Lipcinski D, et al. System for diagnosis of rolling profiles of the railway vehicles. Mech. Syst. and Signal Process. 2014; 48(1-2): 153-161.

[11] Chugui YV. 3D optical measuring technologies for dimensional inspection. J. of Physics: Conf. Series. 2005; 13: 366-372.

[12] Gao Y, Feng Q, Cui J. A simple method for dynamically measuring the diameters of train wheels using a one-dimensional laser displacement transducer. Opt and Lasers in Eng. 2014; 53:158-163.

[13] Zhang ZF, Gao Z, Liu YY, et al. Computer vision based method and system for online measurement of geometric parameters of train wheelsets. Sensors. 2012; 12(1):334-46. 
[14] W. Kaihua, Zhang F, Zhu F, et al. Online measurement for surface defects of running wheelset. In: Pan J, Wyant JC, Wang H, editors. SPIE 6723, 3rd int. symposium on advanced optical manufacturing and testing technologies. Proceedings; 2007 Jan 17; Chengdu, China.

[15] Sanchez AL, Gomez CJ, inventors; Talgo, SA., assignee. Installation and process for measuring rolling parameters by means of artificial vision on wheels of railway vehicles. United States patent US5808906-A. 1998 Sep 15.

[16] Lopez JL, Lorente JJ, inventors; Talgo, Sa., assignee. Installation for measuring the wheel offset of railway vehicles. United States patent US6003232-A. 1999 Dec 21.

[17] Cioboata D, Palade DD, Abalaru A, et al. Wheel profile control and monitoring system. In: WESIC'08, 6th workshop on European scientific and industrial collaboration on promoting advanced technologies in manufacturing. Proceedings; 2008 Sep 25; Bucharest, Romania.

[18] Sanchez A, Gomez C, Navarro R, inventors; Talgo, Sa., assignee. Rolling and lathing parameter measuring device by artificial viewing for railway vehicle wheels. United States patent US2003160193-A1. 2003 Ago 23.

[19] Danneskiold-Samsoee U, Gramtorp J, Haure A, Madsen T, inventors; Caltronic, As., assignee. A plant for track-based detection of the wheel profile of train wheels. International patent WO9012720-A1. 1990 Nov 1.

[20] Mazzola L, Alfi S, Bruni S. Evaluation of the hunting behaviour of a railway vehicle in a curve. In: Iwnicki S, editor. The institution of Mech. Eng. Part F: J. of Rail and Rapid Transit. Proceedings; 2015 July 6; London, UK.

[21] Ruiz OE, Cadavid CA Garcia MJ, et al. Principal component analysis -PCA- and Delone triangulations for PL approximation $\mathrm{C}^{1}$-continuous 1-manifolds in $\mathcal{R}^{\mathrm{N}}$. In: Hamza MH, editor. 7th IASTED Int. Conf. on Computer Graphics and Imaging. Proceedings; 2004 Nov 10; Hawaii, US.

[22] Ruiz OE. Understanding CAD/CAM/CG. American Society of Mechanical Engineers ASME. Continuing Education Institute. Global Training, ASME Code GT-006; 2002.

[23] Boyd JP, Ong JR. Exponentially-convergent strategies for defeating the Runge phenomenon for the approximation of non-periodic functions, part two: Multi-interval polynomial schemes and multidomain Chebyshev interpolation. Applied Numerical Mathematics. 2011; 61:460-472.

[24] Bartels RH, Beatty JC, Barsky BA. An introduction to splines for use in computer graphics \& geometric. San Francisco (CA): Morgan Kaufmann; 1987.

[25] Deuce R. Wheel treads damage - an elementary guide. Görlitz: Bombardier, Inc.; 2007.

[26] Orlova A, Boronenko Y. The anatomy of railway vehicle running gear. In: Iwnicki S, editor. Handbook of Railway Vehicle Dynamics. Boca Ratón (FL): Taylor \& Francis; 2006. p. 39-84.

[27] Shabana AA, Zaazaa KE, Sugiyama H. Railroad vehicle dynamics: A computational approach. London: Taylor and Francis; 2008.

[28] Martinod RM, Betancur GR, Castañeda LF. Identification of the technical state of suspension elements in railway systems. Veh Syst Dyn: Int J Veh Mech Mob. 2012; 50(7): 1121-1135.

[29] Idárraga G, Burgelman N, Meza J, et al. The influence of rail lubrication on energy dissipation in the wheel/rail contact: A comparison of simulation results with field measurements. Wear. 2015; 330-331: 533-539.

[30] Stow J, Andersson E. Field testing and instrumentation of railway vehicles, in Handbook of Railway Vehicle Dynamics. In: Iwnicki S, editor. Handbook of Railway Vehicle Dynamics. Boca Ratón (FL): Taylor \& Francis; 2006. p. 423-456. 
1

2

3

4

5

6

7

8

9

10

11

12

13

14

15

16

17

18

19

20

21

22

23

24

25

26

27

28

29

30

31

32

33

34

35

36

37

38

39

40

41

42

43

44

45

46

47

48

49

50

51

52

53

54

55

56

57

58

59

60

\section{Figures List}

Figure 1. Setup of the measurement system.

Figure 2. Piecewise-defined by polynomial fitting.

Figure 3. Partial-profilogram.

Figure 4. Partial-profilogram $G$, and reference-profilogram $H$.

Figure 5. Reconstructed-profilogram $G_{H}$.

Figure 6. Wear parameters base on reconstructed-profilogram $G_{H}$.

Figure 7. Measuring equipment.

Figure 8. Reconstructed profilogram from experimental tests. 
(1) Wheel

(2) Measuring area

(3) Laser line

(4) Light beam

(5) Laser transducer

(6) Wheel profile

(7) Rail

(8) Distance transducers
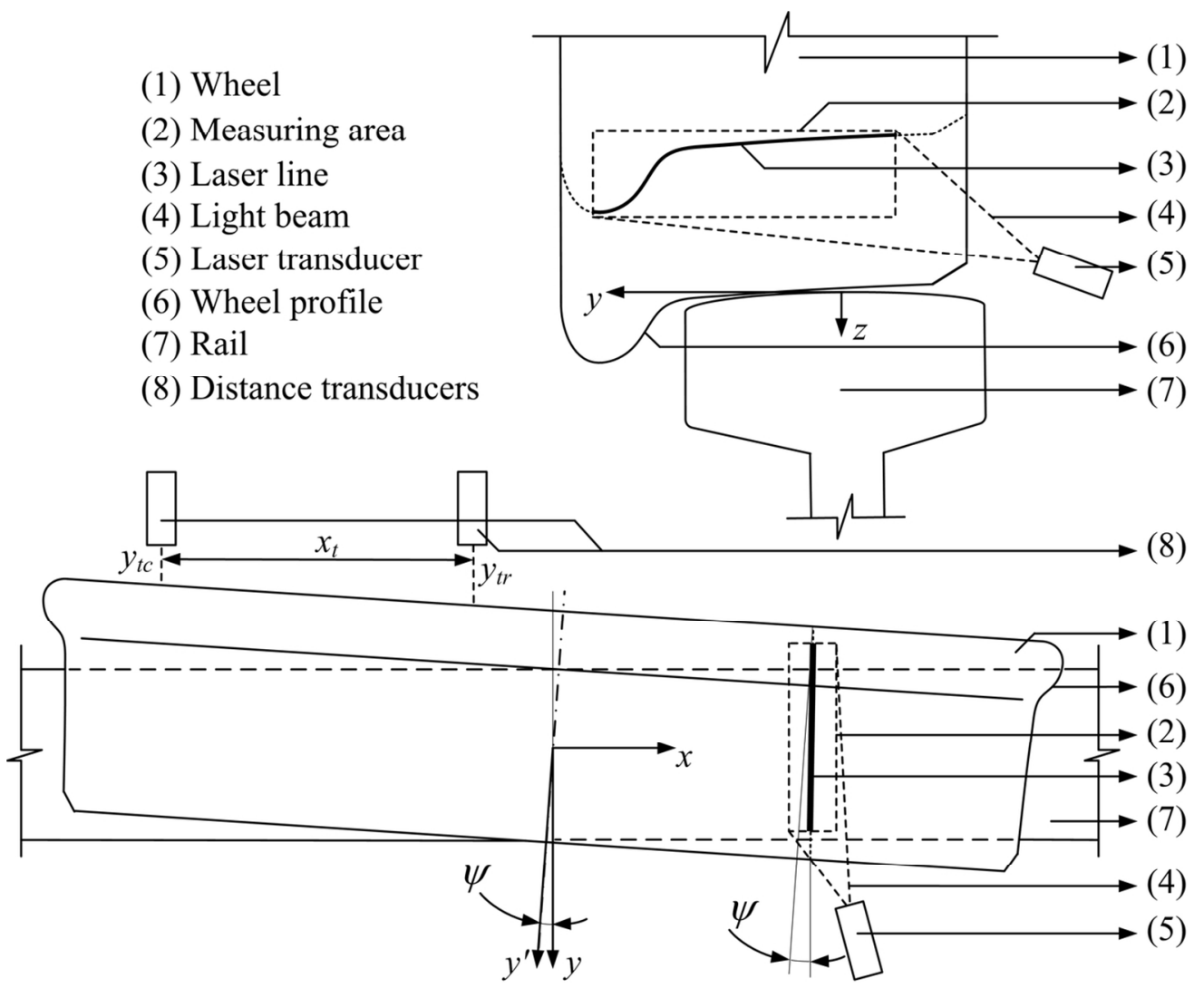

Setup of the measurement system $118 \times 97 \mathrm{~mm}(300 \times 300 \mathrm{DPI})$ 


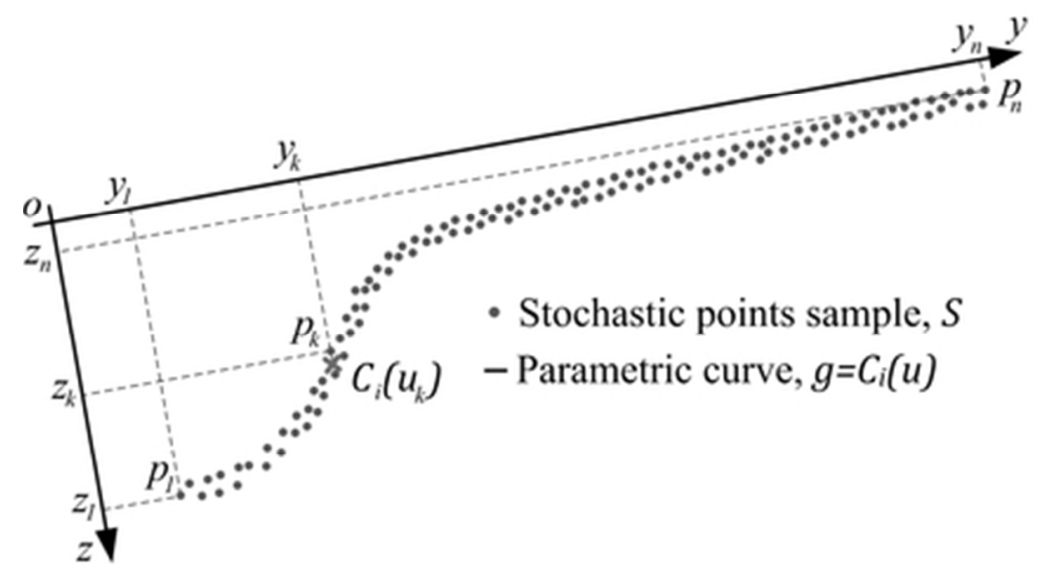

Piecewise-defined by polynomial fitting $46 \times 21 \mathrm{~mm}(300 \times 300$ DPI) 


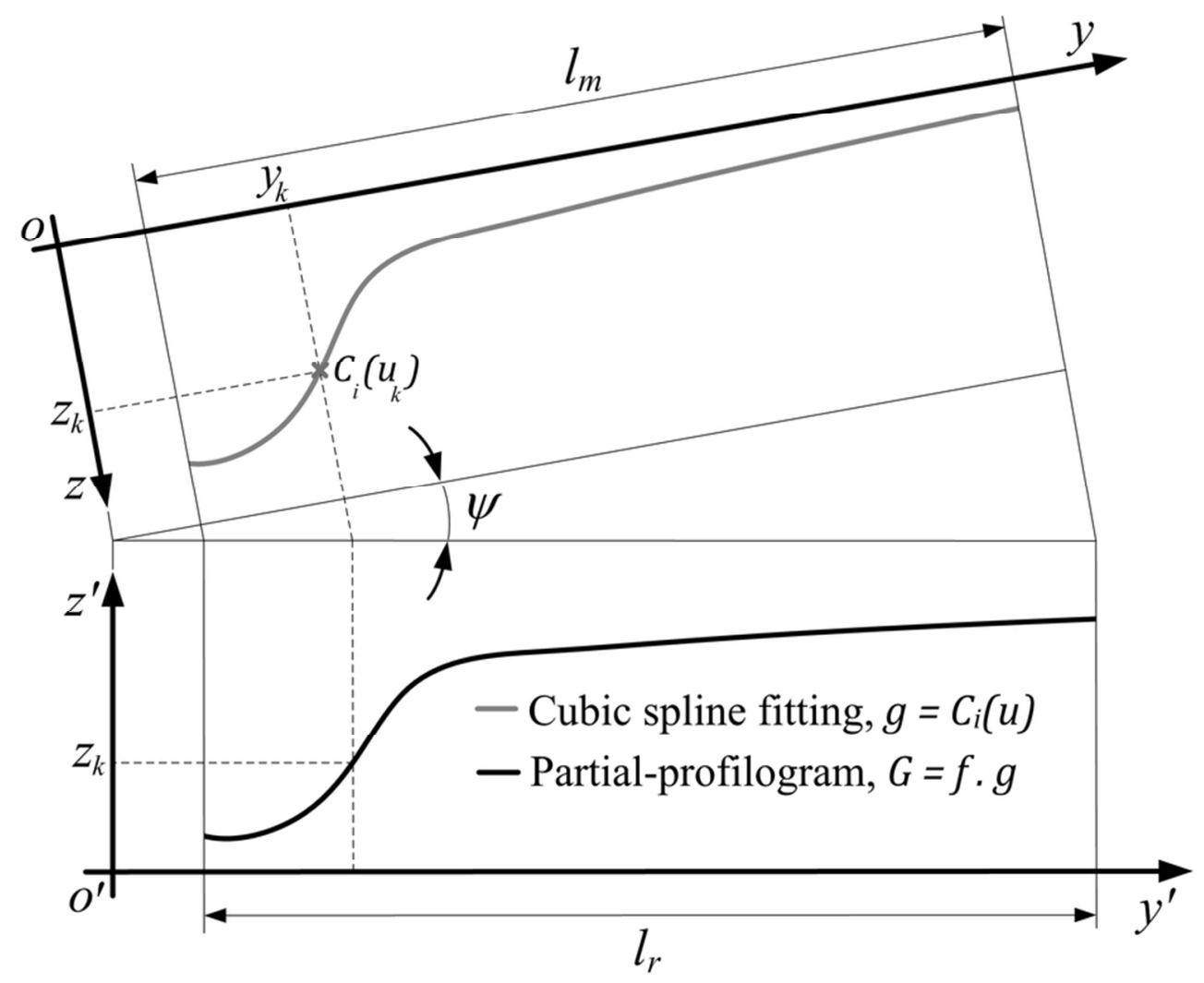

Partial-profilogram

$80 \times 66 \mathrm{~mm}(300 \times 300$ DPI $)$ 
Page 19 of 24

Vehicle System Dynamics

1
2
3
4
5
5
6
7
8
9
9
10
11
12
13
14
15
16
17
17
18
19
20
21
22
23
23
24
25
26
27
2

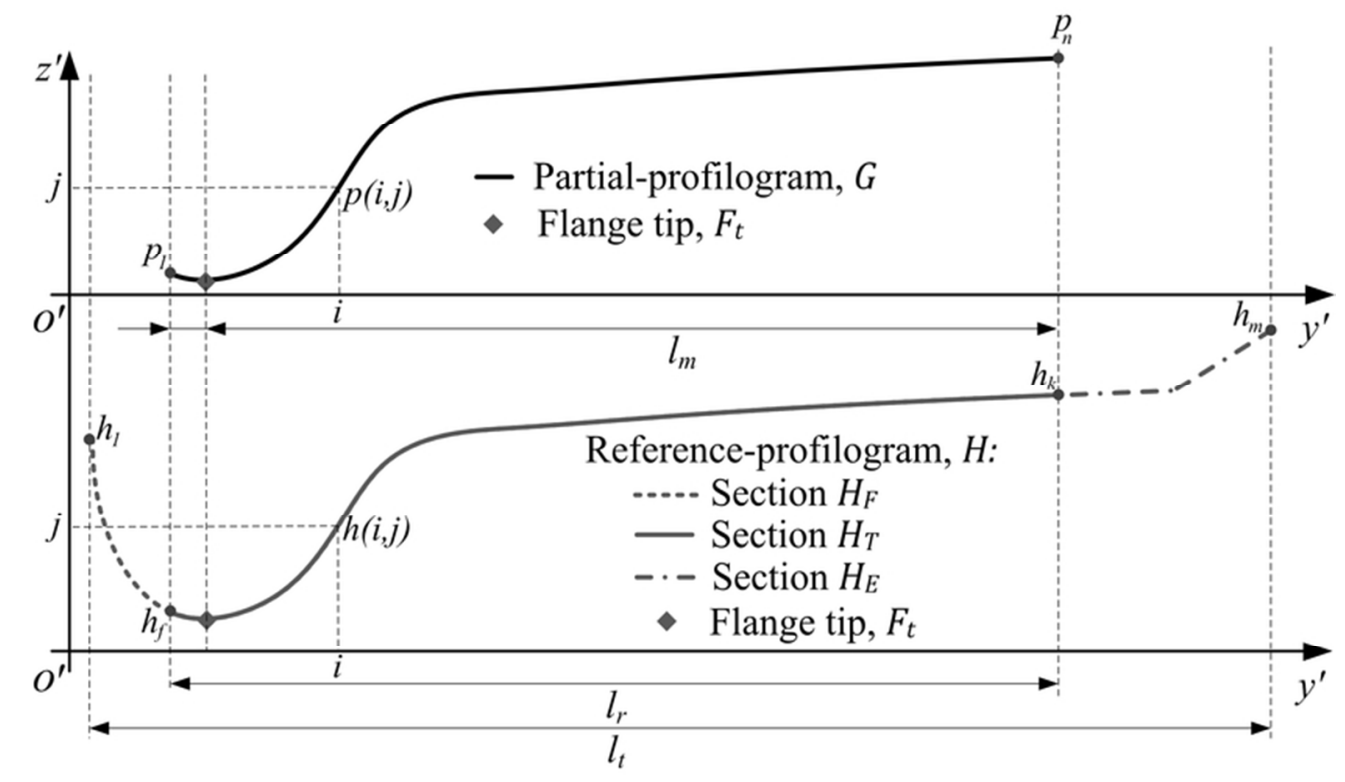

Partial-profilogram $\mathrm{G}$, and reference-profilogram $\mathrm{H}$. $70 \times 42 \mathrm{~mm}(300 \times 300 \mathrm{DPI})$

URL: http://mc.manuscriptcentral.com/nvsd 
Vehicle System Dynamics

Page 20 of 24

1
2
3
4
5
6
7
8
9
10
11
12
13
14
15
16
17
18
19
20
21
22
23
24
25
26
27
28
29
30
31
32
33
34
35
36
37
38
39
40
41
42
43
44
45
46
47
48
49
50
51
52
53
54
55
56
57
58
59
60 


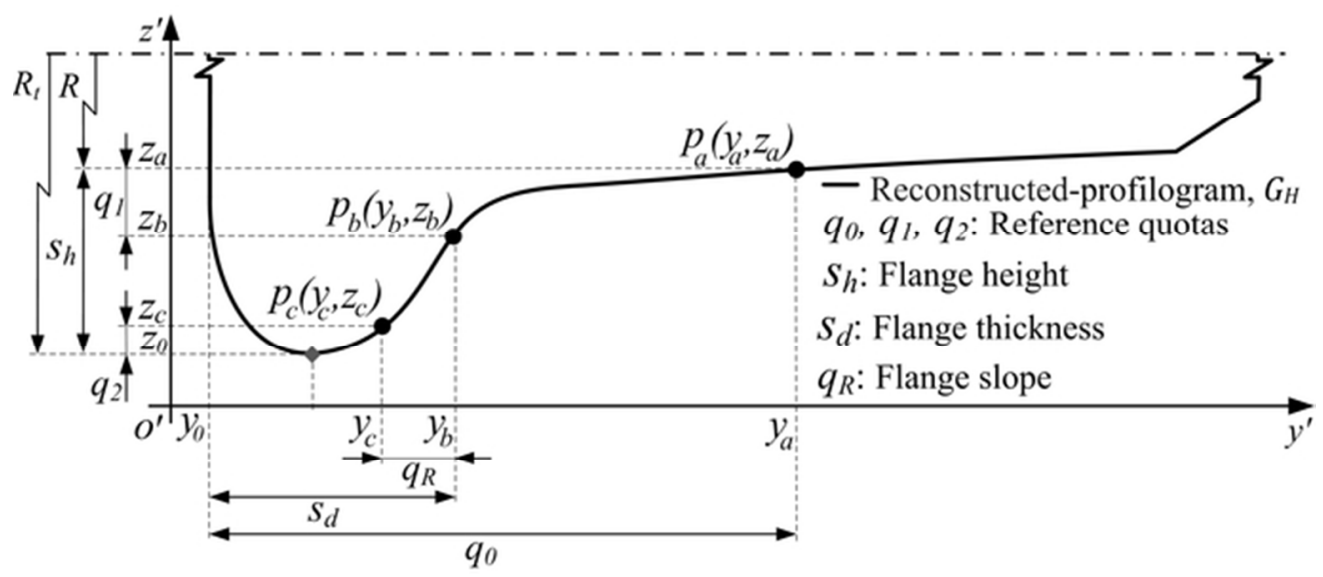

Wear parameters base on reconstructed-profilogram $\mathrm{G}_{\mathrm{H}}$. $57 \times 25 \mathrm{~mm}(300 \times 300 \mathrm{DPI})$ 


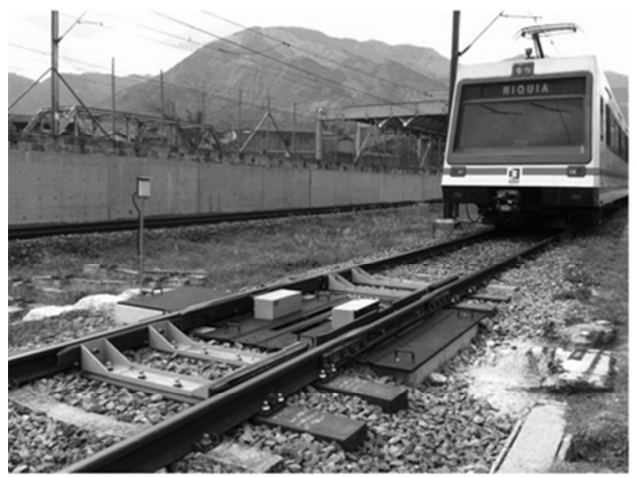

a. Measuring track.

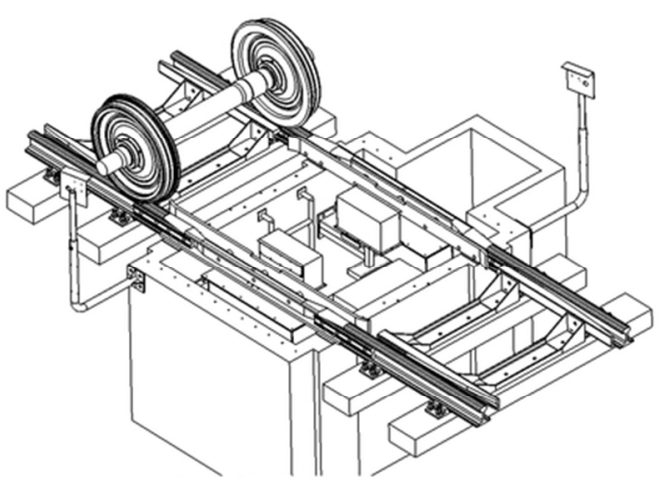

b. Measuring equipment

Measuring equipment. $70 \times 28 \mathrm{~mm}(300 \times 300 \mathrm{DPI})$ 


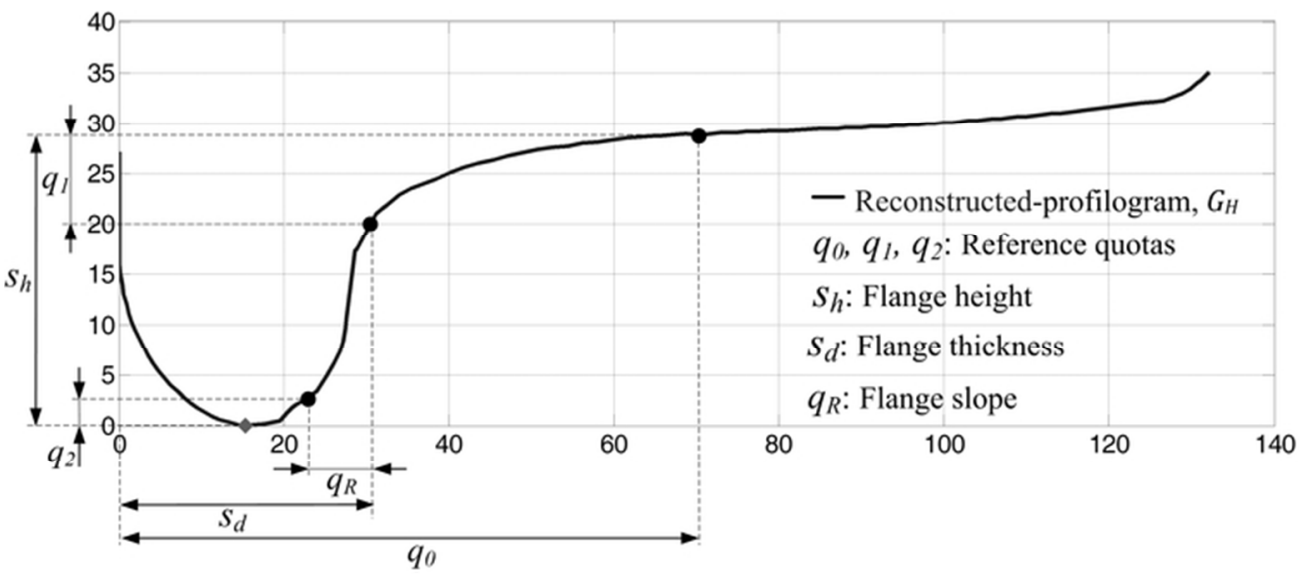

Reconstructed profilogram from experimental tests. $64 \times 27 \mathrm{~mm}(300 \times 300 \mathrm{DPI})$ 
Table 1. Results of the measurements with different equipment.

\begin{tabular}{ccccccc}
\hline & \multicolumn{3}{c}{ Measurement, $M_{i}[\mathrm{~mm}]$} & \multicolumn{2}{c}{ Error, $\varepsilon_{i}[\%]$} \\
\cline { 2 - 5 } \cline { 5 - 6 } Wheel & MiniProf & LazerView & Proposed method & & $\varepsilon_{1}$ & $\varepsilon_{2}$ \\
parameters & $\left(M_{1}\right)$ & $\left(M_{2}\right)$ & $\left(M_{3}\right)$ & & \\
\hline$S_{h}$ & 28.819 & 28.923 & 28.732 & & 0.30 & 0.66 \\
$S_{d}$ & 30.164 & 30.080 & 30.997 & & 2.76 & 3.05 \\
$q_{R}$ & 8.396 & 8.280 & 8.091 & & 3.64 & 2.28 \\
\hline
\end{tabular}

